\title{
Generational differences in nurses' characteristics, job satisfaction, quality of work life, and psychological empowerment
}

\author{
Amy Sparks Coburn, Samantha J. Hall \\ School of Nursing, West Virginia University, Morgantown, WV, United States \\ Correspondence: Amy Sparks Coburn. Address: Robert C. Byrd Health Sciences Center, 6607 Health Sciences South, PO \\ Box 9620, Morgantown, WV, United States. E-mail: amsparks@hsc.wvu.edu \\ Received: February 6, 2014 \\ Accepted: April 16, 2014 \\ Online Published: May 9, 2014 \\ DOI : $10.5430 /$ jha.v3n5p124 \\ URL: http://dx.doi.org/10.5430/jha.v3n5p124
}

\section{Abstract}

Objective: Currently, there are four generations in the nursing workforce. Each generation holds a different set of values that create challenges for managing a multi-generational workforce; these values affect nurses' perceptions of quality of work life (QWL), psychological empowerment (PE), and job satisfaction (JS). The aims of this study are to (1) identify differences in the characteristics of Baby Boomer, Generation X, and Millennial nurses, (2) identify differences in the QWL between Baby Boomer, Generation X, and Millennial nurses, (3) identify differences in JS between Baby Boomer, Generation X, and Millennial nurses, and (4) identify differences in PE between Baby Boomer, Generation X, and Millennial nurses.

Methods: This descriptive, comparative design was conducted via a web-based survey among 223 registered nurses in the USA. Data was collected using Survey Monkey.

Results: Baby Boomers had significantly more years of experience, higher levels of both PE and JS as compared to Generation X and Millennial nurses.

Conclusions: The findings of this study indicate the prominence of RNs' sociological value systems on their perceptions of their workplace. Based on these findings, nurse managers can work to create an environment that is supportive of multiple generations; an environment that enhances PE and, in turn, JS.

\section{Key words}

Generation, Psychological empowerment, Quality of work life, Job satisfaction, Nurses

\section{Introduction}

This non-experimental, comparative study evaluated three generations of nurses' characteristics, job satisfaction, quality of work life, and psychological empowerment. Although the nursing shortage has been, to some extent, alleviated as a result of the recession, healthcare analysts maintain that the duality of an aging nursing workforce and health care consumers will result in a shortage of more than 260,000 nurses by $2025^{[1]}$. With new reforms in health care, many more Americans will have access to the healthcare system, increasing the demand for nurses ${ }^{[2]}$. Additionally, nurse retention and job dissatisfaction continue to plague the profession with currently a $14 \%$ turnover rate in U.S. acute care hospitals ${ }^{[3]}$. 
Nurse retention factors, such as job dissatisfaction and inadequate staffing, have been associated with nurse sensitive quality of care indicators such as decreased patient satisfaction, failure to rescue the patient, adverse patient events, and increased mortality rates ${ }^{[4-7]}$. Job dissatisfaction among nurses can be affected by many factors, with nurse administrators being cited as a key source of nurse dissatisfaction ${ }^{[8,9]}$.

Nurse administrators consistently report retention challenges related to managing a multi-generational workforce such as: younger generations are more dissatisfied, greater difficulty retaining younger generations of nurses, the inability to empower nurses to consistently offer safe and quality care, and a lack of knowledge related to how generations perceive their work ${ }^{[10]}$. With four generations currently in the nursing work force, there may be challenges in ensuring that each generation is satisfied. Different generations present with different values, beliefs, and expectations; which, in turn, influence their perceptions about job satisfaction (JS) ${ }^{[10]}$. Consequently, understanding the link between generational cohorts and JS can lead to enhanced retention strategies.

\subsection{Background}

There are currently four generations of nurses in the work force: Veterans (1922-1943), Baby Boomers (1944-1960), Generation X (1961-1980), and Millennials (1981-2000) ${ }^{[10]}$. Veterans are known as being conservative, loyal, and having respect for authority. Baby Boomers value promotions and titles and are strong willed and competitive. Generation Xers prefer a balance between work and home life. They like to be recognized for their talents, creativity, and expertise. The Millennial generation also likes to have a balance between work and home life, while valuing collaboration and teamwork. This generation is known for being able to easily incorporate technology into their lives ${ }^{[11]}$. Generations differ in their values of certain aspects of the workplace which, in turn, affect their JS. In attempt to capture the generational differences that may most impact quality of nursing care, researchers have examined nurses' JS, quality of work life, and psychological empowerment (PE).

\subsubsection{Generation and job satisfaction}

Significant differences in RN JS among the generational cohorts have been noted in the literature; however, there appears to be discrepancies regarding which generation is more satisfied with their current jobs ${ }^{[12-16]}$. Baby Boomer nurses have reported higher overall JS and significantly less burnout than Generation X nurses ${ }^{[13,14]}$. In a study conducted by Keepnews et al. ${ }^{[15]}$, Baby Boomer nurses were significantly less satisfied with their jobs than Millennial nurses. Inconsistent findings could be related to variations in instruments, generational cohort categories, and sample populations.

\subsubsection{Generation and quality of work life}

Quality of work life (QWL) is the value assigned to one's work context. QWL, in part, has been defined as an ability to satisfy personal needs through work experiences ${ }^{[17]}$, which indicates that QWL directly influences RN JS. Two studies investigated differences in QWL among generations of nurses ${ }^{[16,18]}$; both studies found that generations perceived their quality of their work life differently. More specifically, Generation X nurses perceived higher levels of autonomy than Baby Boomer nurses functioning in similar work environments ${ }^{[18]}$. Interestingly, Baby Boomer nurses ranked autonomy as a higher job satisfier than Generation X nurses ${ }^{[18,19]}$.

\subsubsection{Generation and psychological empowerment}

Psychological empowerment, as defined by Spreitzer ${ }^{[20]}$, is a motivational construct manifested in four cognitions: meaning, competence, impact, and self-determination. This construct is described as an active process in which an individual "feel(s) able to shape his or her work role and context" ${ }^{[20]}$. PE has been identified as a primary predictor of JS and intent to leave a job ${ }^{[21]}$. Generation has also recently been linked to empowerment providing greater insight in to the value associated differences amongst generations. Farr-Wharton et al. ${ }^{[22]}$ conducted a study that examined the relationship between empowerment and generational cohorts among hospital nurses. Empowerment was found to have little impact on Millennial nurses' level of commitment to the workplace. However, empowerment had a significant impact on Baby 
Boomers and Generation X's level of commitment ${ }^{[22]}$. In another study, Baby Boomers reported a higher total PE score than Generation X nurses. Baby Boomers scored significantly higher on the meaning and competence subscales of PE ${ }^{[23]}$.

Much of the research previously conducted has focused on two generations, Baby Boomers and Generation X. There were no studies found that investigated the relationship(s) between nurse characteristics, generation, and RN JS. Additionally, we were not able to find a study that incorporates all of these concepts within one theoretical framework. The concept of PE has not been well studied in relation to generational differences. Further research on the link between PE and generations will allow insight in to the values of each generation. Thus, the aims of this study were to: (1) identify differences in the characteristics of Baby Boomer, Generation X, and Millennial nurses, (2) identify differences in the QWL between Baby Boomer, Generation X, and Millennial nurses, (3) identify differences in JS between Baby Boomer, Generation X, and Millennial nurses, and (4) identify differences in PE between Baby Boomer, Generation X, and Millennial nurses.

\subsubsection{Conceptual framew ork}

The conceptual model for investigation, which includes the concepts of generation, QWL, JS and PE is based on Spreitzer's ${ }^{[20]}$ Psychological Model and the Theory of Basic Human Values ${ }^{[24,25]}$. PE is reflected in the persons' abilities to discover the meaning, enhanced competence, and self-determination necessary to impact their environments. Within the context of this model, it is theorized that work factors and personal characteristics do not necessarily enhance or improve one's PE. Rather, the ability to be empowered is intrinsically motivated, and with optimal PE, persons could find meaning and satisfaction despite their difficult environments. This ability is, however, theorized to be either enhanced or attenuated by how nurses' actual work environments resonate with their value systems.

Value systems are essential to human development and influence persons’ perceptions, choices, and behaviors ${ }^{[24,25]}$. The basis of the theory of basic human values was established by the early works of Rokeach ${ }^{[24,25]}$ who noted that values are intrinsic within persons as well as shared at the societal level. Values are prioritized by persons and serve as the guiding framework for conflict resolution within their lives. Values are developed during the formative years and societal influences ${ }^{[24]}$ and, thus, are shared by generational cohorts ${ }^{[26-30]}$. A generation is a cohort of persons who are broadly socialized together. Generational cohorts are born and raised within the same societal, political, and historical context, shaping a shared belief system based on a similar world view ${ }^{[28,31,32]}$. Because members of a generational cohort experience similar societal influences during the formative years and those societal influences are considered unstable and changing over time, generations have been noted to differ in their values ${ }^{[30]}$. A secondary analysis ${ }^{[30]}$ on data from 979 Canadian knowledge workers identified that Generation X and Baby Boomer nurses differed significantly in their values. Specifically, achievement, hedonism, and stimulation were valued more by Generation X than Baby Boomers; whereas, security, benevolence, universalism, conformity, and tradition were more valued by Baby Boomers. Thus, basic human values theory provides a basis for understanding how socialization impacts generations of persons' value systems.

\section{Methods}

\subsection{Design}

A descriptive, comparative design was conducted via a web-based survey. Links to nursing-focused websites have been found to be an effective recruitment strategy for Web-based nursing research ${ }^{[33]}$. The distribution of invitations to participate was implemented by the following: An invitation to participate in the study and a link to the survey was provided to twelve professional nursing Facebook walls; An invitation to participate in the study and a link to the survey was provided to the allnurses.com/nursing-blogs nursing discussion forum; In addition to web-based recruitment strategies, nurses were invited to participate in the following manner: A listing of national teaching hospitals was identified at www.theagapecenter.com/Hospitals/index.htm. A query letter was e-mailed to the Chief Executive Officer of the nursing department. The letter described the purpose of the study, as well as an invitation for staff nurses at the 
institution to participate. Nurse participants were given the opportunity to submit their names in a gift certificate raffle. The raffle consisted of twenty $\$ 50$ Mastercard gift certificates.

\subsection{Sample}

The inclusion criteria were the following: RN license in the U.S., employed as a direct patient care provider, ability to read English, and access to the Internet. Any data inadvertently collected from nurses outside the United States were not included in this study. The sample demonstrated sufficient power with a total of 223 nurses.

\subsection{Data collection}

Data were collected for this study using Survey Monkey, a Web research management company from October to December 2010. The Unlimited data collection plan the following key features: (1) unlimited questions; (2) custom redirect-upon completion of the survey, participants with any questions or concerns were directed to the researcher's e-mail address; (3) responses collected via Web links; (4) fully accessible data anytime; and (5) downloading of data into an Excel file, reducing costs associated with data entry and eliminating data entry errors.

\subsubsection{Demographics}

A demographics survey included the collection of data on the nurses' age, gender, education, and experience. The survey was based on the 2008 National Sample Survey of Registered Nurses (NSSRN) to allow for comparisons between our sample and a larger national nurse sample.

\subsubsection{Generation}

Nurses participating in the study will be categorized into one of the following generational cohorts based on their provided birth year: Veterans (1922-1943), Baby Boomers (1944-1960), Generation X (1961-1980), and Millennials $(1981-2000)^{[10]}$.

\subsubsection{J ob satisfaction}

The Global Job Satisfaction questionnaire is a 4-item global measure adapted from Hackman and Oldman's ${ }^{\text {[34] }}$ Job Diagnostic Survey ${ }^{[35]}$. The items are measured on a 5-point Likert scale. The instrument has been established as a valid and reliable tool with Cronbach's alphas ranging from $0.78-0.84^{[36]}$.

\subsubsection{Quality of work life}

The NWI-R ${ }^{[37]}$ consists of 49 items rated with a 4-point Likert-type scale measuring nurses' perceptions of selected organizational traits in their work place; specifically, autonomy, control over practice setting, and nurse-physician relationship ${ }^{[38]}$. The Cronbach alphas for three of the subscales, autonomy (0.78), control over the practice setting $(0.79)$, and nurse-physician relations (0.73), were acceptable ${ }^{[38]}$.

\subsubsection{Psychological empowerment}

The Psychological Empowerment Instrument is a 12-item self-report scale with four sub-scales: meaning, selfdetermination, competence, and impact. Each sub-scale has three items measuring the dimension of PE using a 7-point Likert response scale ranging from 1 (very strongly disagree) to 7 (very strongly agree) resulting in a total possible score range of 12-84. High scores indicate high levels of empowerment, which is considered a positive characteristic. The Cronbach's alphas have ranged from 0.74-0.94 amongst the four subscales in the nursing literature ${ }^{[21,36,39-41]}$.

\subsection{Ethical considerations}

The study was approved by the West Virginia University Institutional Review Board. Participants' consent was implied by virtue of completing the on-line survey. Participants' anonymity was protected using the "Web Link Collector" option offered by Survey Monkey. The Web Link Collector method does not track the participants' names or emails. The SSL encryption package was purchased which protects the survey link and survey page during data transmission. 


\subsection{Data analysis}

The statistical package for Social Sciences (SPSS)/Predictive Analytics Software (PASW) Package 18 was used for the analysis in this study. Reliability coefficients (Cronbach's alpha) were performed on the PE ${ }^{[20]}$, NWI-R, and Global JS ${ }^{[35]}$ instruments. Descriptive, Chi-square for independence, and ANOVAs statistical tests were used. Bartlett's test of Sphericity and Kaiser-Meyer-Olkin were run to assess the factorability of the correlation matrix. A post-hoc Tukey analysis procedure was conducted to identify which groups had significant differences. Level of significance was set at 0.05 .

\section{Results}

The sample demographics are provided in Table 1. The majority of nurses in this sample were female (91\%), Caucasion (89.2\%), and BSN prepared (51\%). Distribution statistical analysis found that age (mean $=37.32, S D=11.4$ ) and total years as a $R N$ (mean $=9.01, S D=10.05$ ) were extremely positively skewed, indicating a young sample of nurses. Additionally, the proportion of nurses in each of the generations in this sample were respectively as follows: Baby Boomers 26.9\%, Generation X 38.6\%, and Millennial nurses 34.5\%.

Table 1. Descriptive data for categorical level demographic characteristics $(\mathrm{N}=223)$

\begin{tabular}{|c|c|c|}
\hline Characteristic & Frequency & Percent \\
\hline Gender & 223 & 100 \\
\hline Female & 203 & 91 \\
\hline Male & 20 & 9 \\
\hline Race & 223 & 100 \\
\hline Caucasian & 199 & 89.2 \\
\hline African American & 8 & 3.6 \\
\hline Hispanic & 4 & 1.8 \\
\hline Native American & 2 & 0.9 \\
\hline Asian & 4 & 1.8 \\
\hline Other & 6 & 2.7 \\
\hline Marital status & 222 & 100 \\
\hline Single & 74 & 33.3 \\
\hline Married & 124 & 55.9 \\
\hline Divorced & 19 & 8.6 \\
\hline Widowed & 2 & 0.9 \\
\hline Separated & 3 & 1.4 \\
\hline Education & 223 & 100 \\
\hline Diploma & 8 & 3.6 \\
\hline $\mathrm{ADN}$ & 71 & 31.8 \\
\hline BSN & 114 & 51.1 \\
\hline MSN & 29 & 13.0 \\
\hline $\mathrm{PhD}$ & 1 & 0.4 \\
\hline Generation & 223 & 100 \\
\hline Baby Boomers & 60 & 26.9 \\
\hline Generation X & 86 & 38.6 \\
\hline Millennials & 77 & 34.5 \\
\hline
\end{tabular}


Table 1. (continued.)

\begin{tabular}{|c|c|c|}
\hline Characteristic & Frequency & Percent \\
\hline Years since RN degree & 222 & 100 \\
\hline$<1 \mathrm{yr}$ & 23 & 10.4 \\
\hline $1-5$ yrs & 98 & 44.3 \\
\hline 6-10 yrs & 28 & 12.7 \\
\hline$>10$ yrs & 72 & 32.6 \\
\hline Primary work status & 222 & 100 \\
\hline Emergency & 14 & 6.3 \\
\hline Maternity & 11 & 5.0 \\
\hline ICU & 50 & 22.5 \\
\hline Step down & 27 & 12.2 \\
\hline Medical/Surgical & 48 & 21.7 \\
\hline Skilled nursing & 6 & 2.7 \\
\hline Pediatric & 1 & 0.5 \\
\hline Other & 65 & 29.3 \\
\hline Work status & 213 & 100 \\
\hline Full (36 hrs or more) & 172 & 80.8 \\
\hline Part (20-35 hrs) & 31 & 14.6 \\
\hline Casual (< 20 hrs) & 10 & 4.7 \\
\hline Years in current position & 222 & 100 \\
\hline$<1 \mathrm{yr}$ & 53 & 23.9 \\
\hline $1-2$ yrs & 78 & 35.1 \\
\hline $3-5$ yrs & 34 & 15.3 \\
\hline 6-10 yrs & 32 & 14.4 \\
\hline $10 \mathrm{yrs}$ & 25 & 11.3 \\
\hline Geographic region & 222 & 100 \\
\hline Northeast & 42 & 18.9 \\
\hline Midwest & 31 & 14 \\
\hline West & 20 & 9 \\
\hline South & 129 & 58.1 \\
\hline Salary & 221 & 100 \\
\hline$<\$ 10,000$ & 4 & 1.8 \\
\hline$\$ 10,001-20,000$ & 3 & 1.4 \\
\hline$\$ 20,001-30,000$ & 11 & 5.0 \\
\hline$\$ 30,001-40,000$ & 24 & 10.9 \\
\hline$\$ 40,001-50,000$ & 58 & 26.2 \\
\hline$\$ 50,001-60,000$ & 42 & 19.0 \\
\hline$\$ 60,001-70,000$ & 41 & 18.6 \\
\hline$\$ 70,001-80,000$ & 22 & 10.0 \\
\hline$\$ 80,001-90,000$ & 12 & 5.4 \\
\hline$\$ 90,001-100,000$ & 2 & 0.9 \\
\hline$>\$ 100,000$ & 2 & 0.9 \\
\hline
\end{tabular}

Note. ADN = Associate degree in Nursing, BSN = Bachelor of Science in Nursing, MSN = Master of Science in Nursing, PhD = Doctor of Philosophy

The results for the intergenerational comparisons are found on Table 2. There were significant differences in nurses' educational levels and generation $(\mathrm{Phi}=28.211, p=.000$, Cramer's $\mathrm{V}=0.252)$. The majority (68.8\%) of Millennial nurses 
were BSN prepared, as compared to 35\% of the Baby Boomer nurses who were BSN prepared. Of the total number of Diploma prepared nurses, $75 \%$ of them were in the Baby Boomer generation. However, Baby boomers also had the highest percentage (46.7\%) of MSN prepared nurses.

Table 2. Results from Chi-square tests of independence and ANOVAs comparing baby boomer $(n=60)$, generation $X$ ( $\mathrm{n}=86)$, and millennial $(\mathrm{n}=77)$ nurses.

\begin{tabular}{|c|c|c|c|c|c|}
\hline Variable & Baby Boomers & Gen $X$ & Mill & Statistical Result & $p$ \\
\hline & & & & Phi & \\
\hline Education ${ }^{*}$ & & & & 28.211 & $.000^{*}$ \\
\hline Diploma & $2.7 \%(\mathrm{n}=6)$ & $0.45 \%(\mathrm{n}=1)$ & $0.45 \%(\mathrm{n}=1)$ & & \\
\hline ADN & $8.5 \%(n=19)$ & $14.8 \%(n=33)$ & $8.5 \%(n=19)$ & & \\
\hline BSN & $9.4 \%(n=21)$ & $17.9 \%(n=40)$ & $23.8 \%(n=53)$ & & \\
\hline MSN & $6.3 \%(n=14)$ & $5.4 \%(n=12)$ & $1.8 \%(n=4)$ & & \\
\hline Geographic Region & & & & 1.877 & .931 \\
\hline North/East & $5.9 \%(n=13)$ & $6.3 \%(n=14)$ & $6.8 \%(\mathrm{n}=15)$ & & \\
\hline Midwest & $3.6 \%(n=8)$ & $5.4 \%(\mathrm{n}=12)$ & $4.9 \%(n=11)$ & & \\
\hline South & $13.9 \%(\mathrm{n}=31)$ & $23.8 \%(n=53)$ & $20.3 \%(n=45)$ & & \\
\hline West & $3.2 \%(\mathrm{n}=7)$ & $3.2 \%(\mathrm{n}=7)$ & $2.7 \%(n=6)$ & & \\
\hline Experience $^{*}$ & Mean(SD) & & & F value & \\
\hline (Years) & 20.51(11.49) & $6.46(5.47)$ & $2.68(1.90)$ & 117.59 & $.000^{*}$ \\
\hline \multicolumn{6}{|c|}{ Psychological Empowerment ${ }^{*}$} \\
\hline Overall Score & $5.36(1.01)$ & $4.80(1.02)$ & $4.91(0.84)$ & 6.177 & $.002^{*}$ \\
\hline Meaning & $5.81(1.48)$ & $5.55(1.21)$ & $5.76(1.14)$ & 0.890 & .412 \\
\hline Competence & 6.32(.929) & $5.67(1.25)$ & $5.67(1.04)$ & 7.844 & $.001^{*}$ \\
\hline Impact & $4.25(1.75)$ & $3.15(1.68)$ & $3.32(1.38)$ & 9.068 & $.000^{*}$ \\
\hline Self-Determination & $5.05(1.58)$ & $4.80(1.48)$ & $4.87(1.28)$ & 0.535 & .587 \\
\hline \multicolumn{6}{|l|}{ NWI-R } \\
\hline Overall Score & $2.40(.519)$ & $2.44(.478)$ & $2.34(0.51)$ & 0.849 & .429 \\
\hline Leadership & 39.2(11.5) & 39.5(10.1) & $37.6(9.74)$ & 0.705 & .496 \\
\hline Resources & 26.9(6.95) & $27.6(5.82)$ & 25.8(5.95) & 1.699 & .186 \\
\hline Collaboration & $15.9(4.28)$ & $16.6(3.87)$ & $16.5(4.42)$ & 0.476 & .622 \\
\hline \multicolumn{6}{|l|}{ Job Satisfaction ${ }^{*}$} \\
\hline Overall Score & $3.15(1.12)$ & $2.62(1.05)$ & $2.68(0.92)$ & 5.407 & $.005^{*}$ \\
\hline
\end{tabular}

* significant difference between generations

Baby Boomers were significantly more experienced $(\mathrm{F}=117.589, p<.001)$ and satisfied with their nursing jobs as compared to the Generation $\mathrm{X}$ and Millennial nurses in this sample $(\mathrm{F}=5.407, p=.005)$. Baby Boomers also had significantly higher levels of total PE $(\mathrm{F}=6.177, p=.002)$ than the younger generations. More specifically, Baby Boomers had higher levels of PE subscales: competence $(\mathrm{F}=7.844, p=.001)$ and impact $(\mathrm{F}=9.068, p=.000)$. Overall, Baby Boomers were significantly older, had more years of experience, and higher levels of both PE and JS than Generation X and Millennial nurses $(p<.05)$.

\section{Discussion}

The sample was comprised of a slightly lower proportion of female nurses (91\%) as compared to the nurses who reported currently working (92.6\%) in the 2008 NSSRN (see Table 1). There was a slightly higher proportion of Caucasians (89.2\%) compared to the NSSRN sample (84.9\%). The educational background of this sample in comparison to the 
NSSRN sample, respectively is as follows: Diploma 3.6\% versus 14\%, Associate Degree of Nursing (ADN) 31.8\% versus 35.1\%, Bachelor of Science in Nursing (BSN) 51.1\% versus 34.6\%, Master of Science in Nursing (MSN) 13\% versus $10.9 \%$, and Doctor of Philosophy $(\mathrm{PhD})$ in nursing $0.4 \%$ versus $0.46 \%$. Additionally, the proportion of nurses in each of the generations in this sample and the NSSRN sample were respectively as follows: Baby Boomers $26.9 \%$ versus $56.6 \%$, Generation X 38.6\% versus 30\%, and Millennial nurses 34.5\% versus 9\%. The difference could reflect generational response bias due to the differing data collection methods of this study (web-based survey) and the NSSRN (paper survey).

The finding that older generations had greater years of experience, but less educational preparation than younger generations is consistent with previously published studies ${ }^{[14,42]}$. In this sample, the percentage of BSN-prepared nurses increased with each preceding generation reflecting current national educational trends among nurses. According to the American Association of Colleges of Nursing ${ }^{[43]}$, enrollment in entry-level BSN programs in 2009-2010, increased 6.1\% for the 10th consecutive year. Part of this rise could be attributed to employers placing greater emphasis on highly trained nurses. In addition, younger generations of nurses have greater access to educational programs than older generations had available even a decade ago. Currently, there are approximately 200 more accelerated BSN programs in the nation as compared to the 31 accelerated BSN programs available to nurses in $1990{ }^{[44]}$. One would also anticipate that older generations of nurses would have increased years of experience based simply on increased age and, thus have had a longer time period to work than younger generations.

The finding that Baby Boomers had significantly higher levels of PE than the younger generations consistent with previous research ${ }^{[23]}$. PE has been identified as a predictor of RN JS ${ }^{[21]}$; thus, one would anticipate the finding that generations with significantly higher levels of PE would demonstrate higher levels of RN JS. Despite various work environments, previous research has consistently reported Baby Boomers significantly more satisfied with their jobs than younger generations ${ }^{[12-14]}$. This suggests that each generation's values and the perceived presence of those values in the work environment could be a contributing factor to their JS. Thus, perhaps consideration to what is most valued by each generation would be an effective strategy to retaining younger generations. Additionally, Baby Boomers had significantly higher levels of perceived competence and impact in their work environments further suggesting nurses' satisfaction stems from the confidence and perceived ability to impact their work environments.

Baby Boomers did not differ in their QWL as compared to the Millennial and Generation X nurses; however, Baby Boomers exhibited higher levels of RN JS than the Millennial and Generation X nurses. Although QWL and RN JS were found to be highly correlated, this finding supports the theorized proposition that generations differ in their job values and those value differences could manifest into JS differences regardless of the work environment. In other words, despite the same perceptions of their quality of work life, the younger generations of nurses demonstrated significantly less satisfaction with their jobs. This is consistent with a previously published study that identified RN JS as an outcome of nurses’ perceived quality work life ${ }^{[45]}$.

\subsection{Limitations}

A cross sectional survey design lends to a participant self-selection bias potentially limiting the generalizability of the findings; however, the use of a theoretical framework provides a guide from which speculations regarding conceptual relationships can more confidently be made by the researcher. With survey designs, there is also a threat of falsification of response or identity. Because of the increased anonymity related to internet surveys, data validation procedures are particularly important. When conducting internet surveys, researchers should consider the purposeful inclusion of questions that allow for data verification. A strength of this study was that the questionnaire items allowed for extensive data verification: the IP address of each respondent was cross-referenced with the respondent's self-selected state; the accuracy of the respondent's self-selected generation was verified with the reported age; each of the respondent responses to years of experience, time in current position, years since degree completion, current position, highest degree earned, and salary were collectively compared for feasibility and discrepancies. 


\subsection{I mplications for nursing management}

Based on these findings, nurse managers can work to create an environment that is supportive of multiple generations of nurses. Retention and performance strategies need not necessary be the same for all nurses, rather offering incentive options may enhance the generalizability of administrators approach. Incentive options could be assembled based on what is most meaningful to nurses; such as, a high performing younger generational nurse valuing life balance may have an option to select priority scheduling.

Development of workforce training sessions aimed at understanding the variations amongst generational cohorts could enhance work satisfaction and PE. Working to find value commonalities as a means for developing a set of common patient outcome goals could enhance nurses' sense of ability to impact their work environment. Manufacturing a collective patient outcomes "report card" for units, in which all generations of nurses participate in the prioritization of outcomes, strategies for implementation, and evaluation process may additionally enhance nurses' meaning in their work.

Open discussion forums, when possible, provide opportunities for differing perspectives to be understood. Within, the constraints of 24 hours patient care needs, these forums may be best implemented via asynchronous web-based chat/discussion boards. Providing topic boards to encourage intergenerational and staff comradely may be particularly helpful to the younger generations of nurses who seem less satisfaction and empowered than Baby Boomer generational nurses. Mentorship aimed at promoting, particularly, new nurses' confidence and coping abilities would not only potentially enhance retention efforts and enhance nurses' perceived competency, but also patient outcomes. It seems that we have an opportunity to build intergenerational bridges supporting the healthy expansion of our nursing workforce and, thus enhance the quality of nursing care for our communities.

\section{Conclusion}

Currently, the nursing workforce spans four generations. Each generation holds a different set of values that create challenges for managing a multi-generational workforce; values that influence nurse's perceptions of JS. Little research has been conducted to examine the relationships between PE, quality of work life, and JS in different generations. Baby Boomer nurses were found to have higher levels of PE and JS compared to Generation Xer's and Millennials. However, the three generations were not found to differ in their quality of work life. Based on these findings, nurse administrators can work to create an environment that is supportive of multiple generations; an environment that enhances PE and, in turn, JS.

\section{Acknowledgement}

The authors express gratitude to Dr. June Larrabee, Dr. Cynthia Persily, Dr. Sandjecklin, and Dr. Spreitzer for their mentorship in the development of this work.

\section{References}

[1] Buerhaus P, Averbach D, Staiger D. The recent surge in nurse employment: causes and implications. Health Affairs. 2009; 28(4): 657-668. http://dx.doi.org/10.1377/hlthaff.28.4.w657

[2] ANA: Nursing shortage [Internet]. Silver Spring, MD: American Nurses Association; 2013 [cited 2013 Dec 5]. Available from: http://www.nursingworld.org/MainMenuCategories/ThePracticeofProfessionalNursing/workforce/NursingShortage.

[3] AACN: Impact of nursing shortage on patient care [Internet]. Washington, DC: American Association of Colleges of Nursing; 2011 [cited 2013 Dec 5]. Available from: http://www.aacn.nche.edu/media-relations/nursing-shortage-resources/impact

[4] Aiken LH, Clarke SP, Sloane DM, Sochalski J, Silber JH. Hospital nurse staffing and patient mortality, nurse burnout, and job dissatisfaction. JAMA. 2002; 288(16): 1987-1993. http://dx.doi.org/10.1001/jama.288.16.1987 
[5] Sales A, Sharp N, Li YF, et al. The association between nursing factors and patient mortality in the Veterans Health Administration: The view from the nursing unit level. Medical Care. 2008; 46(9): 938-945. PMid: 18725848. http://dx.doi.org/10.1097/MLR.0b013e3181791a0a

[6] Needleman J, Buerhaus P, Pankratz VS, Leibson CL, Stevens SR, Harris M. Nurse staffing and inpatient hospital mortality. N Engl J Med. 2011; 364(11): 1037-1045. http://dx.doi.org/10.1056/NEJMsa1001025

[7] McHugh M, Kutney-Lee A, Cimiotti J, Sloane DM, Aiken LH. Nurses’ widespread job dissatisfaction, burnout, and frustration with health benefits signal problems for patient care. Health Affairs. 2011; 3(2): 202-210. http://dx.doi.org/10.1377/hlthaff.2010.0100

[8] Tzeng HM. The influence of nurses' working motivation and job satisfaction on intention to quit: an empirical investigation in Taiwan. Int J Nurs Stud. 2002; 39: 867-878. http://dx.doi.org/10.1016/S0020-7489(02)00027-5

[9] Tzeng HM. Satisfying nurses on job factors they care about: a Taiwanese perspective. J Nurs Adm. $2002 b ; 32(6): 306-309$. http://dx.doi.org/10.1097/00005110-200206000-00005

[10] Sherman RO. Leading a multigenerational nursing workforce: Issues, challenges and strategies. Online J Issues Nurs. 2006; 11(2): Manuscript 2.

[11] Wey Smola K, Sutton CD. Generational Differences: Revisiting Generational Work Values for the New Millennium. J Organ Behav. 2002; 23(4): 363-382. http://dx.doi.org/10.1002/job.147

[12] Apostolidis BM, Polifroni EC. Nurse work satisfaction and generational differences. J Nurs Adm. 2006; 36(11): 506-509. http://dx.doi.org/10.1097/00005110-200611000-00003

[13] Widger K, Pye C, Cranley L, Wilson-Keates B, Squires M, Tourangeau A. Generational differences in acute care nurses. Nurs Leadersh. 2007; 20(1): 49-61. http://dx.doi.org/10.12927/cjnl.2007.18785

[14] Wilson B, Squires M, Widger K, Cranley L, Tourangeau A. Job satisfaction among a multigenerational nursing workforce. J Nurs Manag. 2008; 16(6): 716-723. http://dx.doi.org/10.1111/j.1365-2834.2008.00874.x

[15] Keepnews DM, Brewer CS, Kouner CT, Shin JH. Generational differences among newly liscensed registered nurses. Nursing Outlook. 2010; 58: 155-163. http://dx.doi.org/10.1016/j.outlook.2009.11.001

[16] Wieck KL, Dols J, Landrum P. Retention priorities for the intergenerational nurse workforce. Nursing Forum. 2010; $45(1)$ : 7-17. http://dx.doi.org/10.1111/j.1744-6198.2009.00159.x

[17] Brooks BA. Quality of nursing work life in acute care. J Nurs Care Qual. 2004; 19(3): 269-275. PMid: 15326997. http://dx.doi.org/10.1097/00001786-200407000-00014

[18] Stuenkel DL, Cohen J, De la Cuesta K. The multigenerational nursing work force: essential differences in perception of work environment. J Nurs Adm. 2005; 35(6): 283-285. http://dx.doi.org/10.1097/00005110-200506000-00003

[19] Shacklock K, Brunetto Y. The intention to continue nursing: work variables affecting three nurse generations in Austraila. J Adv Nurs. 2012; 68(1): 36-46. http://dx.doi.org/10.1111/j.1365-2648.2011.05709.x

[20] Spreitzer GM. Psychological empowerment in the workplace: Dimensions, measurement, and validation. Acad Manage J. 1995; 38(5): 1442-1465. http://dx.doi.org/10.2307/256865

[21] Larrabee JH, Janney MA, Ostrow CL, Withrow ML, Hobbs GR, Burant C. Predicting registered nurse job satisfaction and intent to leave. J Nurs Adm. 2003; 33(5): 271-283. http://dx.doi.org/10.1097/00005110-200305000-00003

[22] Farr-Wharton R, Brunetto Y, Shacklock K. The impact of intuition and nurse-supervisor relationships on empowerment and affective commitment by generation. J Adv Nurs. 2012; 68(6): 1391-1401. http://dx.doi.org/10.1111/j.1365-2648.2011.05852.x

[23] Sparks A. Psychological empowerment and job satisfaction between Baby Boomer and Generation X nurses. J Nurs Manag. 2012; 20(4): 451-460. http://dx.doi.org/10.1111/j.1365-2834.2011.01282.x

[24] Rokeach M. The nature of human values. New York, (NY): Free Press; c1973. 438p.

[25] Rokeach M. Understanding human values. New York, (NY): Free Press; c1979. 328p.

[26] Whitbeck LB, Gecas V. Value attributions and value transmission between parent and child. Journal of Marriage and Family. 1988; 50: 829-840. http://dx.doi.org/10.2307/352651

[27] Inglehart M, Brown DR. Professional identity and academic achievement--considerations for the admission process. Academic Medicine. 1990; 65(9): S3-4. PMid: 2400493. http://dx.doi.org/10.1097/00001888-199009000-00016

[28] Mannheim B. Gender and the effects of demographics, status and work values on work centrality. Work Occup. 1993 ; $20(1)$ : 3-22. http://dx.doi.org/10.1177/0730888493020001001

[29] Schonpflug U. Intergenerational transmission of values: The role of transmission belts. J Cross Cult Psychol. 2001; 32(2): $174-185$. http://dx.doi.org/10.1177/0022022101032002005

[30] Lyons S, Duxbury L, Higgins C. Are gender differences in basic human values a generational phenomenon? Sex Roles. 2005; 53(9): 763-778. http://dx.doi.org/10.1007/s11199-005-7740-4

[31] Kupperschmidt BR. Multigeneration employees: strategies for effective management. Health Care Manag. 2000; 19(1): 65-76. 
[32] Hu J, Herrick C, Hodgin K. Managing the multigenerational nursing team. Health Care Manag. 2004; 23(4): $334-340$.

[33] Nogueras DJ. Occupational commitment, education, and experience as a predictor of intent to leave the nursing profession. Nurs Econ. 2006; 24(2): 86-93, 55.

[34] Hackman JR, Oldham GR. Development of the Job Diagnostic Survey. J Appl Psychol. 1975; 60: 159-170. http://dx.doi.org/10.1037/h0076546

[35] Laschinger HK, Havens DS. Staff nurse work empowerment and perceived control over nursing practice: Conditions for work effectiveness. J Nurs Adm. 1996; 26(9): 27-35. http://dx.doi.org/10.1097/00005110-199609000-00007

[36] Laschinger HK, Finegan J, Shamian J, Wilk P. A longitudinal analysis of the impact of workplace empowerment on work satisfaction. J Organ Behav. 2004; 25: 527-545. http://dx.doi.org/10.1002/job.256

[37] Sochalski J, Estabrooks CA, Humphrey CK. Nurse staffing and patient outcomes: evolution of an international study. Can J Nurs Res. 1999; 31(3): 69-88. PMid: 10696170.

[38] Aiken LH, Patrician PA. Measuring organizational traits of hospitals: the Revised Nursing Work Index. Nursing Research. 2000; 49(3): 146-153. http://dx.doi.org/10.1097/00006199-200005000-00006

[39] Morrison RS, Jones L, Fuller B. The relation between leadership style and empowerment on job satisfaction of nurses. J Nurs Adm. 1997; 27(5): 27-34. http://dx.doi.org/10.1097/00005110-199705000-00007

[40] Laschinger HK, Finegan J, Shamian J, Wilk P. Impact of structural and psychological empowerment on job strain in nursing work settings: expanding Kanter's model. J Nurs Adm. 2001; 31(5): 260-272. http://dx.doi.org/10.1097/00005110-200105000-00006

[41] DeCicco J, Laschinger H, Kerr M. Perceptions of empowerment and respect: effect on nurses' organizational commitment in nursing homes. J Gerontol Nurs. 2006; 32(5): 49-56. PMid: 16708984.

[42] McNeese-Smith DK, Crook M. Nursing values and a changing nurse workforce: Values, age, and job stages. J Nurs Adm. 2003; 33(5): 260-270. http://dx.doi.org/10.1097/00005110-200305000-00002

[43] AACN: New AACN data show that enrollment in baccalaureate nursing programs expands for the 10th consecutive year [Internet]. Washington, DC: American Association of Colleges of Nursing; 2010 [cited 2013 Dec 5]. Available from: http://www.aacn.nche.edu/news/articles/2010/bacc-growth.

[44] AACN: Accelerated baccalaureate and master's degrees in nursing [Internet]. Washington, DC: American Association of Colleges of Nursing; 2012 [cited 2013 Dec 5]. Available from:

http://www.aacn.nche.edu/media-relations/fact-sheets/accelerated-programs.

[45] Gifford BD. The relationship between hospital unit culture and nurses' quality of work life. Journal of Healthcare Management. 2002; 47(1): 13-25. PMid: 11836962. 